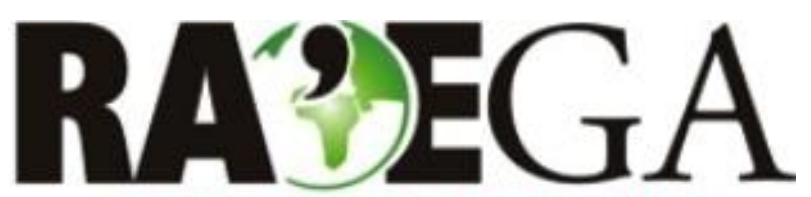

O ESPAÇO GEOGRÁFICO EM ANÁLISE

\title{
VERTICALIZAÇÃO E SOCIABILIDADE: AS RELAÇÕES ENTRE MORADORES DE EDIFÍCIOS RESIDENCIAIS E SUAS FORMAS DE USO E APROPRIAÇÃO DO ESPAÇO
}

\section{VERTICALIZATION AND SOCIABILITY: RELATIONS BETWEEN RESIDENTS OF RESIDENTIAL BUILDINGS AND THEIR WAYS OF USE AND APPROPRIATION OF SPACE}

\author{
Viviane Kraieski de Assunção ${ }^{1}$, Zaira da Silva Conceição ${ }^{2}$
}

\section{RESUMO}

O processo de verticalização avança para as cidades brasileiras de pequeno e médio porte, modificando as formas de habitação e influenciando as relações entre seus moradores. Este processo é consequência do avanço da economia capitalista e está associado a uma nova simbologia de status social, próprios da cultura de consumo da sociedade moderna contemporânea. Este artigo é resultado de uma pesquisa sobre as relações de sociabilidade e formas de uso e apropriação do espaço de moradores de edifícios residenciais no bairro Comerciário, no município de Criciúma, localizado no sul do estado de Santa Catarina, que vem sofrendo um rápido processo de verticalização nas últimas décadas. A investigação buscou compreender os relacionamentos e práticas que surgem a partir das mudanças nas formas de habitação e vizinhança. A pesquisa, de caráter qualitativo, foi realizada por meio de entrevistas semiestruturadas realizadas com trinta moradores do bairro selecionado. A investigação concluiu que a sociabilidade entre moradores de edifícios oscila entre relações superficiais, regidas pela cordialidade e solidariedade, e o individualismo, marcado pelo respeito à privacidade. A praticidade e a segurança dos edifícios, elogiadas pelos sujeitos da pesquisa, são entendidas como características do modo de vida urbano moderno, que inclui a aceleração das atividades rotineiras e a cultura do medo. A pouca utilização dos espaços coletivos aponta para uma falta de apropriação destes espaços, o que torna possível classificá-los como não-lugares.

Palavras-chave: relações de vizinhança; conflito; não-lugar.

\section{ABSTRACT}

The process of verticalization advances to small and medium-sized Brazilian cities, changing the housing forms and impacting the relations between its residents. This process is a result of the advance of the capitalist economy and is associated with a new symbology of social status, characteristics of the contemporary modern society and the consumer culture. This article results from a research on the relations of sociability and ways of use and appropriation of space for residents of residential buildings in Comerciário, neighborhood in the city of Criciuma, located in the southern state of Santa Catarina, which is undergoing a rapid process of verticalization in the last decades. The study aimed at understanding the relationships and practices that arise from changes in the forms of housing and neighborhood. The research, based on a qualitative approach, was carried out through semi-structured interviews conducted with thirty residents of the selected neighborhood. The investigation concluded that sociability between buildings residents oscillates between superficial relationships, governed by the warmth and solidarity, and individualism, marked by respect for privacy. The practicality and safety of buildings, praised by the research subjects, are understood as characteristic of modern urban way of life, which includes acceleration of routine activities and the culture of fear. The little use of collective areas shows a lack of appropriation of these spaces, that can be classified as non-places.

Key-words: neighborhood relations; Conflicts; Non-place

Recebido em: 29/07/2016

Aceito em: 15/02/2017

\footnotetext{
${ }^{1}$ Universidade do Extremo Sul Catarinense, Criciúma/SC, e-mail: vivianekraieski@gmail.com

${ }^{2}$ Universidade do Extremo Sul Catarinense, Criciúma/SC, e-mail: silvazaira2@gmail.com
} 


\section{VERTICALIZAÇÃO E SOCIABILIDADE: AS RELAÇÕES ENTRE MORADORES DE EDIFÍCIOS RESI- DENCIAIS E SUAS FORMAS DE USO E APROPRIAÇÃO DO ESPAÇO}

\section{INTRODUÇÃO}

O processo de verticalização avança para as cidades de pequeno e médio porte brasileiras, e, ao mesmo tempo que modifica as formas de habitação, também influencia as relações entre seus moradores. Este processo teve início nos Estados Unidos, e é consequência do avanço da economia capitalista, marcado por uma crescente densidade populacional nas cidades, maior liberalismo nas legislações locais, preço elevado das terras e propriedades, entre outros fatores (FERREIRA, 2006). Como aponta Somekh (1997), no Brasil, bem como em outros países em desenvolvimento, a verticalização não concretizou o ideal modernista de produção em massa de moradias populares, como solução para um problema social. Ao contrário, a moradia em edifícios foi utilizada como um modelo de modernidade a ser seguido por classes média e alta. Neste sentido, diferentemente de países como a Alemanha, o Brasil "importou" o modelo de verticalização sem incorporar a questão social como objetivo principal, mas como ideia central de um "urbanismo modernizador" (SOMEKH, 1997).

Este modelo está, portanto, também associado a uma nova simbologia de status social, próprios da cultura de consumo da sociedade moderna contemporânea. De acordo com Sahr (2000), as características das grandes cidades passaram a servir de modelos para as cidades de pequeno e médio porte, como sinais de progresso e prosperidade. Neste sentido, a verticalização representa os embates entre o tradicional e o moderno (SAHR, 2000).

Estas transformações ocorridas na morfologia urbana, que romperam com a horizontalidade da cidade (FERREIRA, 2006), não apenas modificaram a paisagem das cidades, como consequência da evolução técnica (RAMIRES, 1998), como também deram origem a mudanças nos relacionamentos entre as pessoas (CARLOS, 1994). Deste modo, o espaço representa não apenas o lócus das relações sociais, que se manifestam através de seu uso e apropriação, como também influencia o desenvolvimento de práticas sociais e apresenta diversas potencialidades (LEFEBVRE, 1992; SCHMID, 2012).

Nos dizeres de Santos (2002), os espaços são constituídos através de objetos e ações. As novas formas de moradia das famílias representam, assim, a construção de novas formas de vizinhança, problematizando a dicotomia entre casa e rua, público e privado (DAMATTA, 1991), ou ainda, entre as esferas coletiva e individual. Coloca-se em questão como as pessoas lidam com a diversidade que é gerada pelas cidades, que aproximam fisicamente indivíduos que manifestam os mais diversos gostos, habilidades e necessidades (JACOBS, 2003), e que são potencializadas por estes arranjos habitacionais modernos.

Considerando estas relações entre verticalização e sociabilidade, foi realizada uma pesquisa com moradores do bairro Comerciário em Criciúma, município localizado no sul do estado de Santa Catarina, com o objetivo de investigar as formas de sociabilidade e de apropriação e uso do espaço de moradores de prédios residenciais. O município possui uma população de 192.308 habitantes, concentrada em uma área de $235,709 \mathrm{~km}^{2}$, o que representa uma densidade populacional de 815,87 $\mathrm{hab} / \mathrm{km}^{2}$ (IBGE, 2010).

Criciúma tornou-se nacionalmente reconhecida, na primeira metade do século $X X$, como "cidade do carvão", devido à atividade carbonífera, principal atividade econômica do município até a década de 1970, quando surgiu o pólo cerâmico no sul do Estado de Santa Catarina. Este pólo começou a entrar em decadência a partir de 1989, com o governo do presidente Fernando Collor de Mello. Na década de 1990, intensificou-se a imigração de criciumenses para os Estados Unidos e países europeus, que passaram a investir no setor imobiliário de sua cidade de origem. Com isso, este setor alcançou um rápido crescimento, que segue até as primeiras décadas do século XXI. Dados do ano de 2010 mostraram que construção civil é um dos principais setores econômicos do município (PREIS, 2012). O 


\section{VERTICALIZAÇÃO E SOCIABILIDADE: AS RELAÇÕES ENTRE MORADORES DE EDIFÍCIOS RESI- DENCIAIS E SUAS FORMAS DE USO E APROPRIAÇÃO DO ESPAÇO}

bairro escolhido para a realização da pesquisa, habitado majoritariamente por moradores de camadas médias, é bastante representativo do avanço do processo de verticalização, resultante do desenvolvimento do mercado imobiliário em Criciúma (Figura 1).

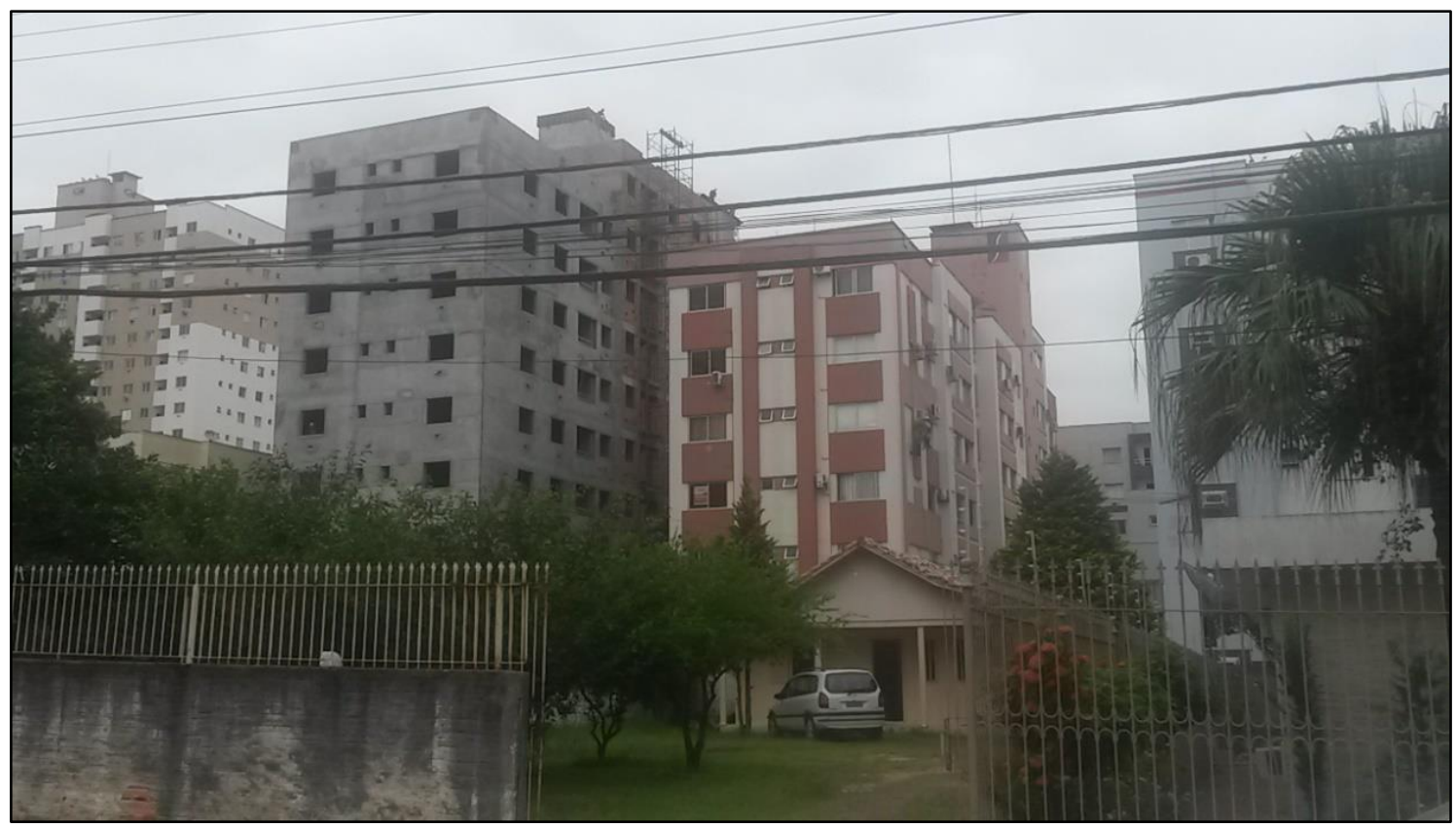

Figura 1 - O bairro Comerciário, em Criciúma, é bastante representativo do avanço do fenômeno da verticalização no município, que altera a paisagem urbana e os modos de sociabilidade entre vizinhos.

Fonte: Autores (2017).

\subsection{SOCIABILIDADE, CONFLITO E CULTURA DO MEDO}

Toma-se como referência o estudo pioneiro de Gilberto Velho (2002), realizado com moradores de um edifício de Copacabana na década de 1970, que caracteriza novas modalidades de relações sociais construídas entre sujeitos de classe média de grandes centros urbanos. Apesar da atualidade do enfoque de Velho, Lopes e Monteiro mostram que os novos condomínios verticais urbanos, diferentemente dos pesquisados pelo antropólogo, apresentam novas configurações, pois não se constituem apenas em locais de residência, passando a incluir uma variedade de serviços e lazer. Neste sentido, estes condomínios tornaram-se "local de socialização ampliada” (LOPES; MONTEIRO, 2009).

Os edifícios residenciais promovem, então, o encontro e a interação entre seus moradores. Como forma de entender estas relações entre os indivíduos, é utilizado aqui o conceito de sociabilidade, tal como definido por Georg Simmel. Para o autor, diferentemente da abordagem durkheiminiana, a sociedade não é exterior aos indivíduos, mas emerge da interação entre eles. Nas palavras de Simmel, a sociabilidade é "o estar com um outro, para um outro, contra um outro que, através do veículo dos impulsos ou dos propósitos, forma e desenvolve os conteúdos e os interesses materiais ou individuais". (SIMMEL, 1983, p. 168).

O conflito é aqui pensado também a partir da perspectiva simmeliana, como uma forma social que emerge das interações entre os indivíduos, podendo apresentar diferentes gradações, e que representa a "negação da unidade" (SIMMEL, 1983). Como já apontado por Lopes (2000) e Lopes e Monteiro (2009), a convivência em condomínios é normatizada por leis, normas sociais e regras internas do condomínio, que, quando descumpridas, costumam causar conflitos nas relações entre os vizinhos. 


\section{VERTICALIZAÇÃO E SOCIABILIDADE: AS RELAÇÕES ENTRE MORADORES DE EDIFÍCIOS RESI- DENCIAIS E SUAS FORMAS DE USO E APROPRIAÇÃO DO ESPAÇO}

Em relação aos usos e apropriações do espaço, a pesquisa procurou contemplar tanto as ações praticadas pelos sujeitos de pesquisa, quanto os sentidos que estes atribuem a estas ações. Deste modo, consideram-se especialmente as dinâmicas estabelecidas nos espaços de uso comum (como elevadores, corredores, hall de entrada, entre outros) dos edifícios residenciais. Estes espaços seriam lugares ou não-lugares? Enquanto os primeiros conformam práticas identitárias, os segundos representam locais de fluxo e passagem, abarcados pela efemeridade e transitoriedade (AUGÉ, 1994). Ou ainda, pode-se pensar em contra-usos (LEITE, 2002) destes espaços, no sentido de que há apropriações singulares que escapam das funções para as quais foram planejados.

Apesar do recorte do objeto de estudo, este não deve ser tomado como "uma unidade fechada e autocentrada", pois se relaciona com outras dimensões da dinâmica urbana e da modernidade (MAGNANI, 1996). Neste sentido, introduzem-se as reflexões de Simmel sobre a vida urbana moderna. Esta, segundo o autor alemão, originou, além de novas formas econômicas, através da circulação do dinheiro, novos comportamentos dos indivíduos e em suas relações com o "outro". Submetidos a intensos estímulos, os citadinos desenvolveram atitudes para lidarem com a nova configuração urbana, como a atitude blasé (indiferença), a reserva e a antipatia (SIMMEL, 2005).

Este contexto urbano passou progressivamente a ser marcado pela desconfiança em relação ao outro, que se reflete nos comportamentos individuais e no uso de dipositivos para garantir segurança, o que, segundo Eckert (2000), é considerado parte do processo civilizador nas cidades. Em nome da segurança pessoal e da violência urbana, mudanças significantes nas relações sociais têm ocorrido nas cidades, legitimadas por atos ou omissões de instituições governamentais, e que geram formas contemporâneas de segregação e homogeneização residencial (GARCIA SANCHEZ; VILLA, 2002).

Deste modo, o espaço é conformado a partir da cultura do medo, que amplia a segregação social. Com base nestes princípios, alguns condomínios residenciais podem ser classificados como "enclaves fortificados" na medida em que são construídas tendo como princípios básicos a segurança, o isolamento, a homogeneidade social, equipamentos e serviços, distanciando-se de outros moradores de classes sociais com menor poder aquisitivo (CALDEIRA, 1997).

Deve-se também considerar que estas mudanças em curso fazem parte da sociedade pós-moderna. A pós-modernidade se manifesta, de acordo com Rouanet, em mudanças do cotidiano, no qual o contato de "pessoa a pessoa" foi substituída pela "relação com um vídeo" (ROUANET, 1987, p. 233). Nas palavras de Bauman, esta sociedade "líquida" caracteriza-se pela diluição de valores sociais e pelo estabelecimento de relacionamentos efêmeros, além de dificuldade de compreensão da subjetividade do outro, o que pode levar a reações de intolerância (BAUMAN, 2007).

\subsection{O BAIRRO COMO ESPAÇO DE SOCIABILIDADE}

Entende-se que $O$ espaço "aqui entendido como o mundo habitado - é um espaço de produção, reprodução e desenvolvimento das sociedades, apresentando-se como um espaço em contínua transformação, quer do ponto de vista dos processos socioculturais, quer da reflexão que sobre ele se faz" (MENEZES, 2000). Essa concepção é consonante com as de Milton Santos, para quem o espaço deve ser entendido como indissociável do tempo, contemplando assim a ação transformadora, e tornando-se o lócus do encontro entre passado e presente (CAMPOS, 2008, p. 156).

Autores como Velho (2002) mostram a ligação de alguns bairros com determinadas camadas ou status sociais. Em certos bairros concentram-se mais moradores de determinada camada social. Pensamos, então, 


\section{VERTICALIZAÇÃO E SOCIABILIDADE: AS RELAÇÕES ENTRE MORADORES DE EDIFÍCIOS RESI- DENCIAIS E SUAS FORMAS DE USO E APROPRIAÇÃO DO ESPAÇO}

que é no espaço que se expressam as hierarquias sociais. Deste modo, o espaço se apresenta como "um verdadeiro campo de forças cuja formação é desigual" (SANTOS, 1978 , p. 122). Como uma totalidade, assim como a própria sociedade que o constitui, o espaço se define como um "conjunto de formas representativas de relações sociais do passado e do presente e por uma estrutura representada por relações sociais que se manifestam através de processos e funções" (SANTOS, 1978, p. 122).

A pesquisa teve, como unidade de análise, o bairro Comerciário. O bairro é denominado Comerciário devido à construção do estádio Heriberto Hulse, no ano de 1955, pertencente ao Comerciário Esporte Clube, que marcou um período de maior ocupação da região. O bairro Comerciário passou a sofrer o processo de verticalização principalmente após a retirada dos trilhos da estrada de ferro que dividia a cidade de Criciúma de leste a oeste. Esta separação também segregava socialmente seus moradores: no lado norte, correspondente à parte mais central da cidade, moravam famílias de maior poder aquisitivo e também era o espaço ocupado pelos comerciantes; já o lado sul, era ocupado por famílias mais pobres, socialmente discriminadas (NASCIMENTO, 2004). Com a remoção da estrada de ferro, a parte sul, que antes era ocupada pela produção agrícola, passou a ser mais valorizada pelo mercado imobiliário, dando início à construção de edifícios. Como expõem Balthazar e Pimenta (2005), residências unifamiliares, construídas há mais de um século, foram substituídas por edifícios com mais de dez pavimentos. A verticalização do local é impulsionada pelo Plano Diretor, como aponta Nazário (2009). Por não ter sido uma área com abertura de minas de carvão, o gabarito do bairro é um dos mais altos em relação às demais regiões do município (NAZARIO, 2009; NASCIMENTO, 2004).

Ezquerra (2013) questiona se ainda devemos tratar de vizinhança ou comunidade urbana no contexto da globalização, quando o sentido de sociabilidade urbana é questionado, e as relações são criadas e mantidas sem necessidade de proximidade física. $O$ autor pontua, no entanto, que, em alguns casos, os bairros continuam sendo uma importante referência de valor e sentimento de pertença para os indivíduos em meio urbano. Essa é a posição de autores como Fonseca (2004), que destacam a importância dos bairros no Brasil e em demais países da América Latina, onde o local de residência está relacionado com a organização social. De acordo com a autora, nestes espaços, apesar das transformações nas cidades, as redes de vizinhança e de parentesco continuam relevantes (FONSECA, 2004).

Definir o conceito de bairro constitui um desafio. Concorda-se com Frúgoli (2013) que o bairro não se trata de um espaço que "apresenta como uma realidade a priori", pois "é marcado por planos e escalas distintos, fronteiras fluidas e alvo de múltiplas representações". Além disso, sua significação pode variar de acordo com os atores sociais, as instituições e as situações em jogo, além dos interesses políticos em questão e do recorte disciplinar adotado (FRÚGOLI, 2013). Ainda que não seja possível apresentar uma definição única e precisa, pode-se entender os bairros como "lugares sociais intermediários entre pequenas unidades de vizinhança e unidades mais amplas" (CORDEIRO, 2001, p. 128), onde se constituem sociabilidades locais, além de relações de solidariedade e de conflito entre seus moradores e entre estes e indivíduos provenientes de outros contextos (CORDEIRO, 2001). Assim como a vida na cidade exige a assimilação de código, o bairro é "uma noção dinâmica que necessita de uma progressiva aprendizagem mediante a repetição do engajamento do corpo do usuário no espaço público até exercer aí uma apropriação" (MAYOL, 2009, p. 41-42).

De acordo com Park (1979), as relações de sociabilidade no meio urbano são construídas principalmente entre vizinhos. Esta afirmação é semelhante a de Mayol, que compreende o bairro como um espaço da 


\section{VERTICALIZAÇÃO E SOCIABILIDADE: AS RELAÇÕES ENTRE MORADORES DE EDIFÍCIOS RESI- DENCIAIS E SUAS FORMAS DE USO E APROPRIAÇÃO DO ESPAÇO}

sociabilidade, "onde se manifesta um 'engajamento' social ou, noutros termos: uma arte de conviver com parceiros (vizinhos, comerciantes) que estão ligados a você pelo fato concreto, mas essencial, da proximidade e da repetição" (MAYOL, 2003, p. 39).

\section{PROCEDIMENTOS METODOLÓGICOS}

A pesquisa realizada é de caráter qualitativo, ou seja, que se dedica ao estudo dos significados, motivações, valores e atitudes que são parte da realidade social de difícil quantificação (GODOY, 1995). Foram realizadas, entre junho de 2015 e fevereiro de 2016, entrevistas semiestruturadas (BAUER; GASKELL, 2002) com 30 sujeitos de pesquisa, moradores do bairro Comerciário, o que corresponde a 30 unidades residenciais. Os indivíduos responderam, entre outras questões, por que foram morar em um prédio residencial, por que escolheram 0 bairro Comerciário, como se relacionam com os vizinhos, se já vivenciaram situações de conflito com os vizinhos, como definem o que é ser um bom vizinho, e se utilizam as áreas de uso comum.

As entrevistas foram gravadas com gravador de voz e realizadas no local de residência dos sujeitos de pesquisa, com exceção de uma delas, que foi entrevistada no local de trabalho. Foi utilizada, como estratégia metodológica, a "bola de neve" - após o contato com a primeira entrevistada, esta indicou as próximas possíveis entrevistadas, e assim sucessivamente.

Os indivíduos entrevistados tinham entre 27 e 74 anos, e moravam no bairro por um período de tempo que variava entre dois e quinze anos. Os entrevistados autoidentificaram-se como indivíduos de classe média, e possuíam profissões diversas, entre profissionais liberais (médico, dentista, advogado) e funcionários públicos. Dos sujeitos da pesquisa, 19 eram proprietários do apartamento onde moravam, e 11 eram locatários.
A análise dos dados foi realizada por meio do método de interpretação de sentidos proposto por Gomes (2010), que segue três etapas: (1) leitura compreensiva das entrevistas e dos registros do diário de campo, de forma a apreender os sentidos de forma geral e particular, identificando temas; (2) agrupamento dos trechos dos registros e das entrevistas em temas, buscando compreender ideias implícitas e explícitas; (3) articulação mais ampla dos sentidos encontrados nos dados com o referencial teórico da pesquisa.

\section{DISCUSSÕES E RESULTADOS}

\subsection{PRATICIDADE E SEGURANÇA}

Os entrevistados afirmaram terem vivido sua infância e parte de sua juventude em casas. Morar em edifícios, portanto, constituía uma mudança que marcava uma nova etapa em seu ciclo de vida: casamento (de acordo com oito entrevistadas mulheres) ou mudança para Criciúma (no caso de doze entrevistados, naturais de outros municípios dos Estados do Paraná e do Rio Grande do Sul, que foram morar na cidade devido a oportunidades de emprego)

Os sujeitos da pesquisa responderam ter escolhido morar em um prédio no bairro Comerciário por causa do valor razoável das propriedades e dos aluguéis e por ser próximo ao comércio (como supermercado e farmácia). Os entrevistados afirmaram valorizar o bairro por ser um local tranquilo, apesar da proximidade com o centro da cidade. A centralização, definida por Heidrich (2013) como o conjunto de benefícios da cidade concentrados em um lugar central, pode ser encontrada em grande parte dos municípios brasileiros, inclusive em Criciúma. Desta forma, a infraestrutura urbana localizada no centro da cidade reúne os serviços de comércio (farmácias, lojas, mercados, entre outros) e outros atendimentos de setores públicos e privados (como consultórios médicos, odontológicos e de outros profissionais de saúde, companhias de água e abastecimento de 


\section{VERTICALIZAÇÃO E SOCIABILIDADE: AS RELAÇÕES ENTRE MORADORES DE EDIFÍCIOS RESI- DENCIAIS E SUAS FORMAS DE USO E APROPRIAÇÃO DO ESPAÇO}

energia elétrica, sistema bancário, entre outros).

Quando perguntados sobre os motivos que os levaram a optar por morar em edifícios residenciais, os sujeitos da pesquisa responderam que foi devido à praticidade e à segurança.

A praticidade, como um valor da modernidade, permite a rotina se desenvolva com maior rapidez. Como afirma Ortiz, a rapidez permeia a vida dos homens. "No mundo moderno o tempo é uma função da inter-relação de um conjunto de atividades, entre elas: morar, vestir, fazer compras, trabalhar, passear etc. adaptar-se ou não a seu ritmo passa a ser uma questão fundamental. Perder tempo significa estar em descompasso com a ordem das coisas" (ORTIZ, 1994, p. 83). Nesse sentido, a vida doméstica em um apartamento seria "mais prática", como explicou um entrevistado: "em uma casa, você tem que cuidar da casa, do jardim... Em um apartamento, é tudo mais fácil, e é mais seguro".

A importância da segurança foi apontada por todos os sujeitos da pesquisa, e foi ressaltada por dois indivíduos que moram sozinhos: "Se eu tivesse uma família, marido e filhos, talvez pensasse em morar em uma casa. Mas, assim, sozinha, eu prefiro morar em um apartamento. Dá menos trabalho... E eu teria medo de morar em uma casa sozinha..." Deste modo, a moradia em prédios residenciais adequa-se ao modo de vida individualista e aos arranjos de família contemporâneos, principalmente dos últimos trinta anos, que, apesar da heterogeneidade, passam a ser caracterizados pelo menor número de filhos por casal, e pela presença apenas da mãe e ou do pai com filho ou filhos em uma unidade residencial (GOLDANI, 1993, 1994).

Esses discursos sobre a sensação de insegurança, presente nas falas dos entrevistados, são comuns a moradores de outros contextos urbanos. Nenhum dos sujeitos da pesquisa afirmou já ter sido vítima de nenhuma forma de crime, como roubo e assalto. Varela (2005, p. 154) considera que o medo do delito já é um problema maior do que a própria ocorrência do delito, na medida que o temor em ser vítima da criminalidade atinge uma quantidade maior de cidadãos, com consequências severas. Outros autores afirmam a existência de um imaginário (TEIXEIRA; PORTO, 1998) ou uma cultura do medo (ECKERT, 2000), que emergem, principalmente, nas cidades no final do século $\mathrm{XX}$, e alteram os modos de vida dos indivíduos.

Ainda que os moradores afirmem ter maior sensação de segurança vivendo em prédios residenciais, esta pode não estar totalmente garantida. Como expõem Lopes e Monteiro (2009), nos condomínios, entendidos enquanto agrupamentos sociais, há um pacto baseado não em laços de comprometimento, coletividade e bem-estar, mas em um acordo para usufruir as vantagens associadas a esse tipo de moradia. A segurança, deste modo, não está garantida, pois não há controle social, que seria resultante de um comprometimento entre os integrantes deste agrupamento. Este controle social seria característico das comunidades, e depende de uma maior proximidade com os outros, o seria incompatível com o individualismo da vida urbana moderna (LOPES; MONTEIRO, 2009, p. 08). Ressalta-se que a abordagem desses autores supera a perspectiva do senso comum, que restringe a segurança pública à necessidade de policiamento ou à presença de dispositivos, como câmeras de segurança, em espaços públicos e privados.

\subsection{RELACIONAMENTOS E CONFLITOS ENTRE VIZINHOS}

Apenas cinco sujeitos da pesquisa sendo dois deles síndicos do condomínio relataram conflitos entre os vizinhos. Estes conflitos teriam sido provocados, principalmente, por dois fatores: (1) o descumprimento das regras do condomínio, como estender o tapete na janela e estacionar o carro fora dos limites estabelecidos para cada morador, e (2) o barulho, ocasionado pelo uso 


\section{VERTICALIZAÇÃO E SOCIABILIDADE: AS RELAÇÕES ENTRE MORADORES DE EDIFÍCIOS RESI- DENCIAIS E SUAS FORMAS DE USO E APROPRIAÇÃO DO ESPAÇO}

de sapatos de salto alto, reuniões festivas ou o latido de cães.

Cinco entrevistadas, moradoras de um prédio onde moram apenas doze famílias, disseram que o fato dos moradores morarem no local há bastante tempo (o tempo de moradia no edifício entre estas entrevistadas variava entre sete e 24 anos) facilitava a convivência entre os moradores e diminuía os conflitos. Outras duas entrevistadas, moradoras de um condomínio onde moram 17 famílias, fizeram afirmações semelhantes.

Os entrevistados foram perguntados sobre o que considerariam ser um bom vizinho. Segundo eles, um bom vizinho seria alguém que "não incomoda", respeita a privacidade dos demais vizinhos, mas que estaria disposto a ajudar quando solicitado. Como exemplos desta ajuda, os sujeitos da pesquisa citaram situações diversas, como avisar o vizinho quando a garagem é inundada pela água das chuvas ou ficar com o filho pequeno quando a mãe tem que comparecer a reuniões. Ainda ressaltaram que estes favores são feitos entre "vizinhos de porta", com quem estabelecem relações de maior proximidade.

Em relação ao que consideram ser necessário para uma boa convivência, os sujeitos da pesquisa destacaram o respeito às normas do condomínio e à privacidade. A valorização da privacidade, de acordo com Sennet (1999), acompanhada do silêncio e do enaltecimento da intimidade, é resultante de um processo histórico que se inicia no século $X V I I I$, e que se intensifica no século XX. Esse processo levaria os indivíduos a "uma vida pessoal desmedida e de uma vida pública esvaziada" (SENNET, 1999, p. 30). A arquitetura do século $X X$ passa a prover espaços para o resguardo da intimidade, o que decorre em uma diminuição das interações sociais: "quanto maior a intimidade, menor a sociabilidade" (SENNETT, 1999, p. 325).

A necessidade do respeito às normas remete à obra de Émile Durkheim (2001). O sociólogo francês entende que a vida em sociedade depende do cumprimento de normas sociais. Os seres humanos, ao longo de suas vidas, deparam-se com estas normas que não foram necessariamente criadas por eles, mas que devem ser seguidas para que a vida social seja possível. Ainda de acordo com Durkheim, os seres humanos são coagidos e pressionados a seguirem essas regras sociais por meio de sanções, que condicionam os comportamentos. Durkheim entende que a sociedade como um organismo, no qual cada uma de suas partes deve desempenhar seu papel para sua própria manutenção, o que remete a uma concepção de uma necessária coesão.

As normas de um condomínio parecem indicar a manutenção de uma vida comum em um espaço compartilhado, sem, no entanto, efetivarem uma maior coesão entre o grupo, como pretendia Durkheim. Neste sentido, têmse um maior individualismo, que restringe a solidariedade a pontuais trocas de favores.

Retomando as concepções de Simmel anteriormente apresentadas, entende-se conflito como inerente às relações sociais. Neste sentido, pode-se afirmar que a ausência de conflito é resultado também do enfraquecimento dos laços entre vizinhos. Uma forma de evitação do conflito é a negação do outro. "Eu nem sei quem são meus vizinhos" foi uma afirmação feita por, pelo menos, quinze dos trinta sujeitos da pesquisa.

Ainda de acordo com Simmel, os sentidos e a percepção sensorial têm um papel importante na interação entre os sujeitos. O pensador alemão afirma que a audição seria o segundo sentido em grau de relevância, atrás apenas da audição, e teria, como os outros sentidos, valores sociológicos. Dentre estes valores, estaria o de ser um instrumento de reconhecimento. Pode-se afirmar que o barulho ocasionado por um vizinho, além de eventualmente causar incômodo, evidencia sua presença.

Almeida considera, citando Prost, que a proximidade espacial, propicia um conhecimento mútuo, pelo menos, aproximativo. Deste modo, os habitantes 


\section{VERTICALIZAÇÃO E SOCIABILIDADE: AS RELAÇÕES ENTRE MORADORES DE EDIFÍCIOS RESI- DENCIAIS E SUAS FORMAS DE USO E APROPRIAÇÃO DO ESPAÇO}

definiriam quem é conhecido de quem é intruso. Este último seria equivalente à posição do estrangeiro analisada por Simmel: a figura de um indivíduo que é reconhecido como tal, apesar de ninguém conhecê-lo. Os sujeitos da pesquisa apontaram que, devido à frequência dos encontros nos corredores e elevadores dos condomínios, reconhecem aqueles que são moradores. Mas, no entanto, não estabelecem com frequência uma relação além da cordialidade. Como uma das entrevistas afirmou: "eu dou bom dia, boa tarde, boa noite, para todo mundo. Com a maioria dos vizinhos é assim. A gente é educada, se cumprimenta, comenta sobre o tempo... Mas nada muito além disso." Esses cumprimentos prestam-se a formas de reconhecimento do outro. No entanto, não estabelecem laços mais profundos entre os indivíduos.

Deste modo, estas relações são caracterizadas pelo afastamento da noção de pessoalidade, que, de acordo com Prado (1987), seria próprio de pequenas cidades, onde o reconhecimento, "no sentido de saberse quem é quem" está atrelado à confiança "na medida que todos são identificados, ou rapidamente identificáveis, pela relação com alguém" (PRADO, 1987, p. 52).

Nesse sentido, a pesquisa corrobora com as conclusões de Lopes e Monteiro (2009) de que os laços construídos entre moradores de um condomínio são superficiais, o que não caracteriza como o agrupamento social como uma comunidade, no sentido sociológico clássico. Os vizinhos em condomínios, ainda que mantenham relações cordiais, com trocas de cumprimentos e pequenos favores, não desenvolvem, via de regra, relações mais profundas. Enquanto a interação com membros da família e amigos é voluntária e intencional, os encontros com os vizinhos limitam-se à interação entre as crianças e outras atividades compartilhadas. Deste modo, os moradores separam o tipo e o nível de intimidade, restringindo as relações a encontros ocasionais (LOPES; MONTEIRO, 2009).
Pesquisas realizadas desde a década de 1970, em países europeus, voltadas a compreender os relacionamentos entre os habitantes das cidades, já apontavam para essa diferenciação dos laços sociais entre os indivíduos. Bulmer (1985), baseando-se em trabalho não publicado do sociólogo britânico Philip Abram, afirma que a amizade é uma relação que ocorre por meio da escolha dos indivíduos, e exige comprometimento, confiança e um conhecimento mais profundo do outro. ${ }^{3}$ Já as relações cordiais, como as de vizinhança, são caracterizadas pelas relações casuais e contingentes. Para tornarem-se amigos, os indivíduos precisam romper as barreiras da privacidade, segundo o autor, que também esclarece que vizinhos podem se tornar amigos, caso essa passagem da privacidade para a intimidade seja negociada (1985, p. 52). A negociação desses limites entre vizinhos seria mais difícil de ser controlada devido à proximidade física entre da moradia dos indivíduos.

Bulmer (1985) cita ainda a pesquisa de Keller, que também aponta para as diferenças entre vizinhos, parentes e amigos. Como explicaram os sujeitos da pesquisa realizada no Reino Unido, "se eu precisar de algo emprestado, eu posso pedir a um vizinho, mas se eu tiver um problema real, eu procuro meus amigos". Ainda baseando-se no trabalho de Keller, Bulmer esclarece que se perde um amigo cometendo falhas com ele; deixa-se de ser vizinhos, mudando-se para outra localidade, e perde-se um parente apenas através da morte (KELLER, 1968, p. 27 apud BULMER, 1985, p. 52).

Estes estudos buscaram caracterizar as mudanças nos padrões de vizinhança, colocando-as nos embates entre tradição e modernidade, como a pesquisa realizada por Abram, realizada na década de 1970. Segundo o pesquisador, a vizinhança tradicional seria

\footnotetext{
3 O autor utiliza as palavras da língua inglesa friendliness, para caracterizar relacionamentos cordiais, e friendship, que seria o equivalente à amizade, que compreende as relações mais profundas.
} 


\section{VERTICALIZAÇÃO E SOCIABILIDADE: AS RELAÇÕES ENTRE MORADORES DE EDIFÍCIOS RESI- DENCIAIS E SUAS FORMAS DE USO E APROPRIAÇÃO DO ESPAÇO}

formada pela imobilidade geográfica e por densas redes sociais formadas por parentes, vizinhos e amigos. Nesse tipo de vizinhança, os vizinhos desempenham funções limitadas, mas importantes, como o exemplo popularmente conhecido de "emprestar uma xícara de açúcar", ou prestar assistência em casos de emergência. Deste modo, há uma rede que provê cuidados recíprocos, que seria resultado de um envolvimento, confiança e cálculo entre os indivíduos. Em momentos de crise, em condições sociais específicas, quando os recursos são escassos, estas relações desempenhariam um importante papel (BULMER, 1985).

Já a vizinhança moderna seria caracterizada por maior mobilidade entre os vizinhos, nas quais os relacionamentos seriam mais marcados pela escolha do que pelo constrangimento. Nesse tipo de vizinhança, alguns indivíduos seriam mais propensos a estabelecerem relações mais próximas com os vizinhos, como as crianças, mães jovens (principalmente aquelas que não possuem emprego nem transporte próprio), aposentados (especialmente os que possuem dificuldades de locomoção e os que moram há um longo período na mesma vizinhança), recém-chegados (principalmente os jovens e que não possuem fortes laços com parentes), e aqueles que possuem algum interesse em mobilizar ação social na vizinhança (BULMER, 1985, p. 51-52).

A pesquisa realizada com moradores de prédios residenciais no bairro Comerciário revelou a presença tanto de características da vizinhança moderna quanto da tradicional, o que mostra a necessidade de se complexificar esse debate, percebendo as nuances de forma não-dicotômica. De fato, nos prédios onde a pesquisa foi realizada, a presença de aposentados, que vivem há mais de cinco anos, foram apontadas como uma das causas da tranquilidade e da boa convivência entre os vizinhos, embora os sujeitos da pesquisa tenham afirmado não desenvolver formas de interação mais profundas. Nesse sentido, a constante mobilidade de moradores em um edifício representaria uma maior possibilidade de geração de conflitos. Por outro lado, percebe-se que as relações entre os vizinhos são menos densas, e restritas aos vizinhos "de porta", que trocam pequenos favores reciprocamente.

A metáfora da porta foi utilizada por Simmel (1996) para tratar da dissociação e do religamento que estão presentes de forma constante na relação dos sujeitos com os outros e com o mundo. A porta pode ser utilizada a partir de diferentes intenções tanto para entrar quanto para sair, embora sua função de separação seja mais acentuada. Em um espaço delimitado por paredes, como um apartamento, os sujeitos podem utilizar a porta para tanto para ultrapassar esses limites quanto para reforça-los, impedindo a entrada de outros.

\subsection{VERANEIO: A CASA DE PRAIA COMO SEGUNDA RESIDÊNCIA}

Apesar de relatarem sobre os benefícios de morar em edifícios, vinte e cinco dos trinta entrevistados afirmaram que, durante os meses de temporada do verão, eles vão com suas famílias para casas localizadas em praias próximas de Criciúma. Os sujeitos da pesquisa contaram que vão para as casas de praia por causa da alta temperatura no município e para descansar do modo de vida mais agitado da cidade. Uma delas, que possui um motorhome, relatou que tem a necessidade de ter mais contato com a natureza e de ter uma "visão ampla" quando abre a porta de casa, o que não seria possível em um edifício. Algumas entrevistadas contaram que adquiriram o hábito de irem para a casa de praia quando tinham filhos pequenos em período de férias, e que mantém este hábito ainda hoje.

Barbosa e Costa (2012, p. 483) apontam que, "com a grande devastação da natureza na atual fase do capitalismo, elementos que outrora eram abundantes hoje se tornam cada vez mais raros, sobretudo no meio urbano, tais como a água potável, o ar 


\section{VERTICALIZAÇÃO E SOCIABILIDADE: AS RELAÇÕES ENTRE MORADORES DE EDIFÍCIOS RESI- DENCIAIS E SUAS FORMAS DE USO E APROPRIAÇÃO DO ESPAÇO}

puro e o verde". Nesse sentido, há um "retorno à natureza", que é reflexo da vida urbana atual, o que torna os municípios litorâneos atraentes por serem considerados espaços de lazer e tranquilidade, paralelo a uma apropriação da natureza pelo mercado imobiliário. Lefebvre (2001, p. 117) considera que o "direito à natureza" tornou-se uma prática social relacionada ao lazer, que se torna uma mercadoria e oferece um contraponto ao "barulho, a fadiga, o universo 'concentracionista' das cidades (enquanto que a cidade apodrece ou explode)."

A prática do veraneio pode ser compreendida como uma prática que surge a partir da Segunda Revolução Industrial, no século XIX, e está relacionado a uma nova forma de conceber e dividir o tempo: o tempo do trabalho e o tempo do não-trabalho. As atividades de lazer começam a fazer parte das rotinas de famílias que passam a ter tempo livre com a mecanização dos processos produtivos, o que é definido por Dumazedier como "dinâmica produtiva do lazer". O lazer significa a liberação do trabalho imposto pelas indústrias para os operários, acompanhado de outras mudanças socioculturais que avançam para um maior individualismo que diminuição dos controles institucionais (DUMAZEDIER, 1979). Para as crianças, é a liberação do período escolar. Esse lazer, principalmente para classes média e alta, vai estar associado a estadas em paisagens consideradas ideais para tal finalidade, como as praias.

No Brasil, o direito a um repouso anual é instituído no governo Vargas na década de 1930, o que vem acompanhado de outras mudanças de costumes trazidas pela modernidade. Como explica Sevcenko (1998, p. 563), as férias são também um período para que os indivíduos "escapem" dos controles impostos na vida diária: "dos familiares, dos vizinhos, das hierarquias, dos papeis sociais e das reservas de conduta". Neste sentido, é possível concluir, partindo dos relatos dos sujeitos da pesquisa, que o veraneio representa também uma maior liberdade e liberação do modo de vida associado à vida urbana que se desenvolve cotidianamente em edifícios residenciais. Além de articular formas de conceber o tempo, também representa essas concepções associadas ao espaço.

No Brasil, estas mudanças de costume também está associado ao fenômeno do turismo de segunda residência, que se expande a partir da década de 1950 no contexto do desenvolvimentismo, com a implementação de empresas multinacionais automobilística no país, acompanhada do aumento da malha viária ligando grandes centros urbanos a regiões que anteriormente eram de difícil acesso. Nesse período, também ocorre a emergência de camadas médias urbanas, que passam "a incorporar entre seus valores socioculturais a ideologia do turismo e do lazer" (BECKER, 1995, p. 10).

A segunda residência possui "repercussões socioespaciais" e constitui "símbolo de status social, característica de camadas sociais alta e, majoritariamente, média (ASSIS, 2003, p. 112). Essas práticas deram início à procura por imóveis no litoral, que está relacionado ao crescimento econômico e à especulação imobiliária, além do desenvolvimento de novos espaços de sociabilidades para as camadas médias urbanas (MACHADO, 2013). Esse fenômeno é identificado no litoral sul de Santa Catarina, com o crescimento econômico de municípios como Balneário Rincão, emancipado em 2013, localizado a 27 quilômetros de Criciúma. A proximidade ao centro urbano, onde está localizada a residência principal, é um dos fatores que influenciam na escolha do local da segunda residência, o que contribui para sua ocupação durante o tempo livre, como os finais de semana e as férias anuais (TULIK, 1998).

\subsection{ESPAÇOS COLETIVOS COMO NÃO- LUGARES}

Os vínculos sociais, para além do espaço privado da moradia, ocorrem em espaços públicos. Segundo Almeida (2011), baseando-se na obra de Prost, "seria basicamente nos encontro banais do dia-dia, 


\section{VERTICALIZAÇÃO E SOCIABILIDADE: AS RELAÇÕES ENTRE MORADORES DE EDIFÍCIOS RESI- DENCIAIS E SUAS FORMAS DE USO E APROPRIAÇÃO DO ESPAÇO}

que os habitantes, de um determinado local estabeleceriam vínculos mais afetivos". Os locais públicos, como as calçadas, praças e bares, constituiriam estes espaços privilegiados para a convivência e a construção de relações mais íntimas entre os habitantes da cidade (ALMEIDA, 2011). Sugere-se aqui uma analogia entre os espaços públicos e as áreas de uso coletivo dos prédios residenciais: seriam estas locais de encontros e formação de vínculos entre os vizinhos?

Em relação à utilização desses espaços coletivos, os entrevistados afirmaram não utilizá-los com frequência. Apenas três entrevistadas relataram que usavam um pátio interno, com brinquedos para crianças, para brincar com os filhos ou netos. Os espaços coletivos mais utilizados, segundo os entrevistados, são a garagem e o salão de festas - este último quando há reuniões de condomínio. De forma semelhante às conclusões de Lopes e Monteiro (2009), a pesquisa demonstrou que a participação dos moradores em reuniões condomínio é pequena, e está restrita aos moradores que são proprietários dos apartamentos onde vivem.
Os corredores, elevadores e o hall dos edifícios foram apontados pelos sujeitos da pesquisa como locais de passagem, nos quais trocam breves cumprimentos com os vizinhos.

É preciso ponderar que os edifícios onde foi feita a pesquisa, embora tivessem sido construídos em diferentes períodos, que variavam entre dez e vinte e cinco anos, apresentam a racionalidade na economia e aproveitamento do espaço. Suas áreas de uso comum não parecem ter sido projetadas para o encontro entre seus moradores. Ao contrário, apenas alguns halls de entrada que possuem sofás e os salões de festas, parecem ter a potencialidade de proporcionar essas interações, embora não sejam utilizados com estes fins por seus moradores. Ao contrário, os salões de festas (com exceção das reuniões de condomínio) são usados para momentos de festividade dos moradores com seus parentes e amigos, o que raramente inclui seus vizinhos. Neste sentido, sugere-se que esses espaços coletivos, como garagem, corredores e halls de entrada (Figura 2), possam ser pensados como não-lugares, pois representam locais de passagem.
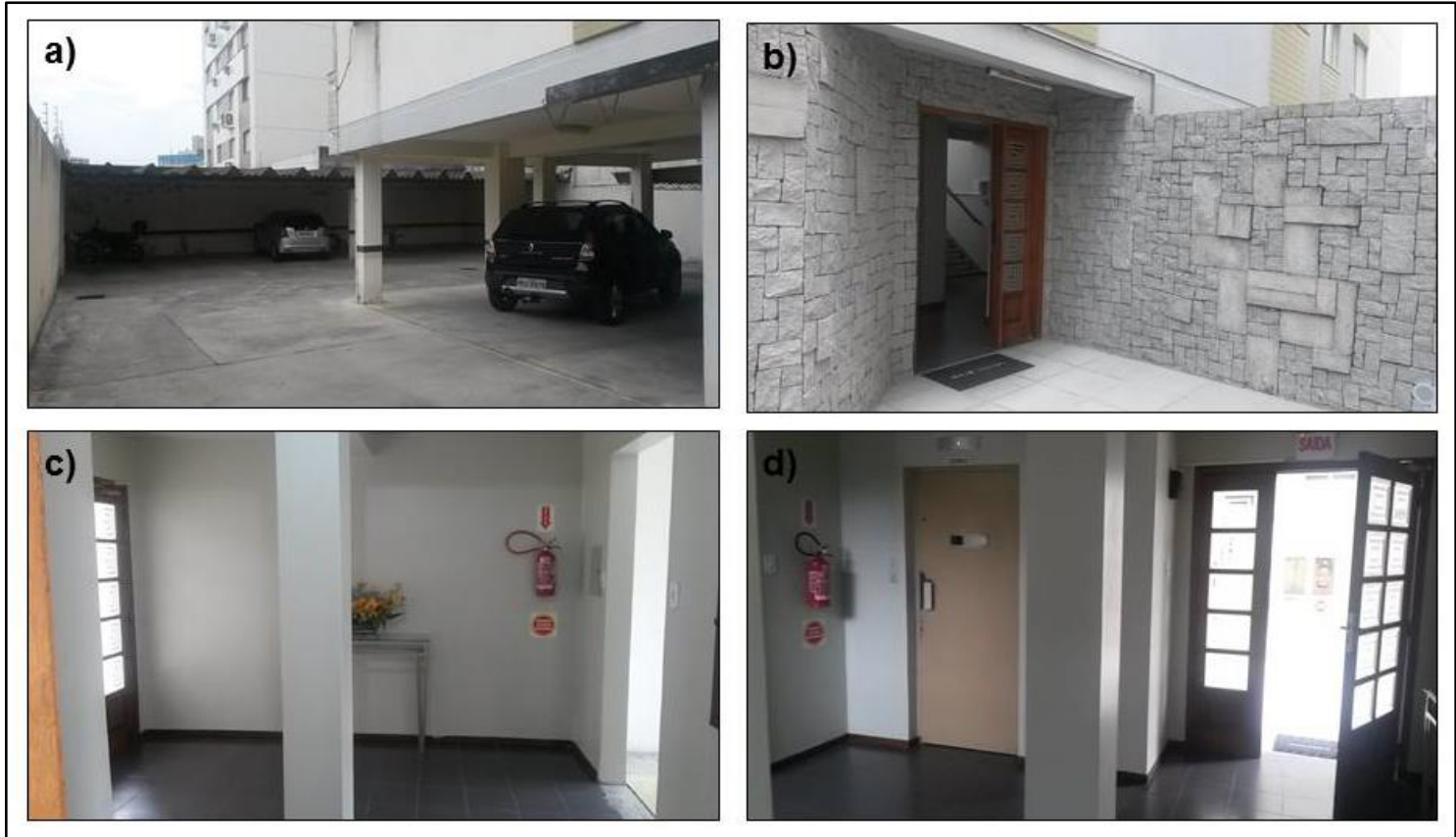

Figura 2 - De acordo com os sujeitos da pesquisa, espaços coletivos, como a garagem (a), o hall de entrada (b, d) e os corredores (d), são espaços de passagem onde ocorrem encontros ocasionais com os vizinhos. Fonte: Autores (2017). 


\section{VERTICALIZAÇÃO E SOCIABILIDADE: AS RELAÇÕES ENTRE MORADORES DE EDIFÍCIOS RESI- DENCIAIS E SUAS FORMAS DE USO E APROPRIAÇÃO DO ESPAÇO}

Augé diferencia os não-lugares dos

lugares antropológicos. No primeiro, a interação entre os sujeitos ocorre por meio de uma "contratualidade solitária", ou seja, as relações estão restritas a certos fins, como ocorre em aeroportos, centros comerciais, entre outros. O espaço e o tempo adquirem especificidades próprias: enquanto o espaço é organizado de forma mais racional, o tempo é encurtado. Nas palavras de Augé, os nãolugares não comportam uma sociedade orgânica, apontando para uma relação entre espaço e as formas de interação que lá se estabelecem. Neste caso, as relações são fugazes e impermanentes. Já nos lugares antropológicos, há o desenvolvimento de relações de sociabilidade, e a construção de uma relação identitária dos sujeitos com o espaço.

\section{CONSIDERAÇõES FINAIS}

$A$ pesquisa concluiu que a sociabilidade entre moradores de edifícios oscila entre relações regidas pela cordialidade e solidariedade, marcada por cumprimentos, breves conversas e pela troca de pequenos favores, e o individualismo, reforçado pelo respeito à privacidade. A praticidade e a segurança dos edifícios, elogiadas pelos sujeitos da pesquisa, podem ser entendidas como características do modo de vida urbano moderno, que inclui a aceleração das atividades rotineiras (ORTIZ, 1994) e a cultura do medo (ECKERT, 2000). É possível afirmar que as restritas relações entre moradores contribuem para reforçar a sensação de insegurança, por não proporcionar possibilidades de controle social. Já essa sensação de insegurança, por sua vez, também limita o estabelecimento de relações mais profundas entre os sujeitos. Estas relações mais superficiais se refletem na e são reflexões $d a$ pouca utilização dos espaços coletivos, que aponta para uma falta de apropriação destes espaços, o que os levam a ser classificados como não-lugares (AUGÉ, 1994).

\section{REFERÊNCIAS}

ALMEIDA, A. P. Uma análise sobre sociabilidade, cotidiano e vizinhança em um bairro popular de João Pessoa-PB. Ponto Urbe [Online], 9 | 2011. Disponível em: $\quad$ http://pontourbe.revues.org/287. Acesso em: 05 jul. 2016.

ASSIS, L. F. Turismo de segunda residência: a expressão espacial do fenômeno e as possibilidades de análise geográfica. Revista Território, Rio de Janeiro, n.11, 12 e 13, set./out. 2003.

AUGÉ, M. Não-lugares: introdução a uma antropologia da supermodernidade. Campinas: Papirus, 1994.

BALTHAZAR, L. F.; PIMENTA, M. de C. A. Criciúma: memória e vida urbana. In: SCHEIBE, L. F.; FURTADO, S. M. de A.; BUSS, M. D. (Org.). Geografias Entrelaçadas: Ambiente rural urbano no sul de Santa Catarina. Criciúma: Ed. da UNESC, 2005. p.193-226.

BARBOSA, A. G.; COSTA, A. A. O solo urbano e a apropriação da natureza na cidade. Sociedade \& Natureza, ano 24 n. 3, p. 477-488, set/dez. 2012.

BAUER, M. W; GASKELL, G. Pesquisa Qualitativa com texto, imagem e som. Um manual prático. 2ed. Petrópolis, RJ: Vozes, 2002.

BAUMAN, Z. Vida Líquida. Rio de Janeiro: Jorge Zahar, 2007.

BECKER, B. K. Levantamento e avaliação da política federal de turismo e seu impacto na região costeira. Brasília: Ministério do Meio Ambiente, dos Recursos Hídricos e da Amazônia Legal, 1995.

BULMER, M. Neighbours and Friends: Sociability, Isolation and Loneliness as factor in the differential provision of neighbourhood care. International Journal of Sociology and Social Policy. Vol. 5, Iss 3, p. $51-66,1985$. 


\section{VERTICALIZAÇÃO E SOCIABILIDADE: AS RELAÇÕES ENTRE MORADORES DE EDIFÍCIOS RESI- DENCIAIS E SUAS FORMAS DE USO E APROPRIAÇÃO DO ESPAÇO}

CALDEIRA, T. P. do R. Enclaves fortificados: a nova segregação urbana. Novos Estudos Cebrap, São Paulo, n.47, p.155-176, mar./ 1997.

CAMPOS, R. R. A natureza do espaço para Milton Santos. Geografares, n. 6, p. 155165, 2008.

CARLOS, A.F.A. A (re)produção do espaço urbano. São Paulo: Editora da Universidade de São Paulo, 1994.

CORDEIRO, G. Í. Territórios e identidades sobre escalas de organização sócio-espacial num bairro de Lisboa. Revista Estudos Históricos, Rio de Janeiro, n. 28, p. 1-16, 2001.

DA MATTA, R. A casa e a rua. Rio de Janeiro: Guanabara Koogan, 1991.

DUMAZEDIER, J. Sociologia empírica do lazer. São Paulo: Perspectiva, 1979.

DURKHEIM, É. As regras do método sociológico. São Paulo: Martin Claret, 2001.

ECKERT, C. A cultura do medo e as tensões do viver a cidade: narrativa e trajetória dos velhos moradores de Porto Alegre. lluminuras, 18, 2000.

FONSECA, C. Família, fofoca e honra: etnografia das relações de gênero e violência em grupos populares. 2a ed. Porto Alegre: Editora da UFRGS, 2004.

EZQUERRA, A. Does it have any sense talking about "neighborhood" in the global city? Reflections on the relationship between sociology, urban community and place. Revista Española de Sociologia, Issue 19, p. 49-66, 2013.

FERREIRA, C. de S. O Edifício Sant'Anna e a Gênese da Verticalização em Campinas. Arquitextos, no 078.3. São Paulo, Portal Vitruvius, nov. 2006.
Disponível em: www.vitruvius.com.br/arquitextos/arq078/ arq078_03.asp. Acesso em 17 julho 2014.

FRUGOLI JR., H. Relações entre múltiplas redes no Bairro Alto (Lisboa). Rev. bras. Ci. Soc., São Paulo, v. 28, n. 82, Jun. 2013. 1.2.

GARCIA SANCHEZ, P.edro; VILLA, M. Vigilant Sociability and Private Urbanism. Residential Homogenization, Urban Practices and Citizenship in Caracas. Perfiles Latinoamericanos, Vol.10(20), p. 207-242, 2002.

GODOY, A. S. Introdução à pesquisa qualitativa e suas possibilidades. Revista de Administração de Empresas, São Paulo, v. 35, n. 2, p. 57-63, 1995.

GOLDANI, A. M. As famílias no Brasil contemporâneo e o mito da desestruturação. Cadernos Pagu, v. 1, p. 67-110, 1993.

GOLDANI, A. M. As famílias brasileiras: mudanças e perspectivas. Cadernos de Pesquisa, n. 91, p. 7-22, 1994.

GOMES, R. Análise e interpretação de dados em pesquisa qualitativa. In: Minayo, M. C. de S. (Org.). Pesquisa social: teoria, método e criatividade. 29. ed. Petrópolis, RJ: Vozes, 2010. p. 79-112.

HEIDRICH, Á. L. Compartilhamento e Microterritorialidades do Espaço Social Metropolitano. Cidades, Vol. 10, N. 17, p. 76-106, 2013.

IBGE (INSTITUTO BRASILEIRO DE GEOGRAFIA E ESTATÍSTICA). Cidades@. Disponível em:

http://www.cidades.ibge.gov.br/xtras/perfi I.php?lang=\&codmun=420460\& search=san ta-catarina|criciuma. Acesso em: 17 julho 2014.

JACOBS, J. Morte e vida de grandes cidades. São Paulo: Martins Fontes, 2003. 


\section{VERTICALIZAÇÃO E SOCIABILIDADE: AS RELAÇÕES ENTRE MORADORES DE EDIFÍCIOS RESI- DENCIAIS E SUAS FORMAS DE USO E APROPRIAÇÃO DO ESPAÇO}

LEITE, R. P. Contra-usos e espaço público: notas sobre a construção social dos lugares na ManguetownContra-usos e espaço público: notas sobre a construção social dos lugares na Manguetown. Rev. bras. Ci. Soc., São Paulo, v.17, n.49, 2002. Disponível em: http://www.scielo.br/scielo.php?script=sci _arttext\&pid=S010269092002000200008\&lng=en\&nrm=iso. Acesso em: 17 Julho 2014.

LEFEBVRE, H. The Production of Space. Oxford: Basil Blackwell, 1991.

LEFEBVRE, H. O direito à cidade. São Paulo: Centauro, 2001.

LOPES, A., MONTEIRO, C. Novas faces da sociabilidade em condomínios residenciais no Brasil. Anais dos Encontros Nacionais da Anpur, v. 13, 2009.

MACHADO, J. R. O veraneio de antigamente: Ipanema, Tristeza e os contornos de um tempo passado na zona sul de Porto Alegre. Revista LatinoAmericana de História. Vol. 2, no. 7, Set. 2013.

MAYOL, P. "Morar". In: CERTEAU, M.; GIARD, L.; MAYOL, P. A invenção do cotidiano: 2. morar, cozinhar. Petrópolis: Vozes, 2009. p. 35-185.

MENEZES, M. Do espaço ao lugar. Do lugar às remodelações sócio-espaciais. Horizontes Antropológicos. Vol. 6, n. 13, 2000.

NASCIMENTO, D. As curvas do Trem. A presença da Estrada de Ferro no Sul de Santa Catarina. Criciúma: UNESC, 2004.

NAZÁRIO, T. G. O homem e seu entorno sociofísico: um estudo sobre o processo de morar e habitar de moradores de edifícios residenciais na cidade de CriciúmaSC. 2009. 259 f. Dissertação (Mestrado) Universidade do Extremo Sul Catarinense, Programa de Pós-Graduação em Ciências Ambientais, Criciúma, 2009.
PARK, R. E. A cidade: Sugestões para a investigação do comportamento humano no meio urbano. In: VELHO, Gilberto. (Org). O fenômeno Urbano. Rio de Janeiro: Guanabara, 1979. p. 25-66

PRADO, R. Cidade Pequena: Paraíso e Inferno da Pessoalidade. Cadernos de Antropologia e Imagem, n. 4, p. 31-56, 1995.

PREIS, Eduardo. Plano diretor participativo de Criciúma / SC: Uma década de conflitos. 2012. 182 f. Tese (Doutorado) - Curso de Geografia, Universidade Federal de Santa Catarina, Florianópolis, 2012.

RAMIRES, J. C. de L. O processo de verticalização das cidades brasileiras. Boletim de Geografia, v. 16, n. 1, p. 97105, 1998.

SAHR, C. L. L.. Dimensões da Análise da Verticalização: exemplos da cidade média de Ponta Grossa/PR. Revista de História Regional, Verão 2000. Disponível em: http://www.revistas2.uepg.br/index.php/r $\mathrm{hr} /$ article/view/2094. Acesso em: 17 Julho 2014.

SANTOS, M. Por Uma Outra Globalização. Rio de Janeiro: Record, 2002.

SENNETT, Richard. O Declínio do Homem Público: as tiranias da intimidade. São Paulo: Companhia das Letras, 1999.

SEVCENKO, Nicolau. História da Vida Privada no Brasil. República: da Belle Époque à Era do Rádio. Vol. 3. Porto Alegre: Companhia das Letras, 1998.

Schmid, C. A teoria da produção do espaço de Henri Lefebvre: em direção a uma dialética tridimensional. GEOUSP - Espaço e Tempo, São Paulo, №32, pp. 89- 109, 2012.

SIMMEL, G. A natureza sociológica do conflito. In: MORAES FILHO, Evaristo (org.). Simmel, São Paulo, Ática, 1983. 


\section{VERTICALIZAÇÃO E SOCIABILIDADE: AS RELAÇÕES ENTRE MORADORES DE EDIFÍCIOS RESI- DENCIAIS E SUAS FORMAS DE USO E APROPRIAÇÃO DO ESPAÇO}

SIMMEL, G. O conflito como sociação. (Tradução de Mauro Guilherme Pinheiro Koury). RBSE - Revista Brasileira de Sociologia da Emoção, v. 10, n. 30, pp. 568573, 2011.

SIMMEL, G. A ponte e a porta. Política e Trabalho, n. 12, p. 10-14, set. 1996.

SIMMEL, G. As grandes cidades e a vida do espírito (1903). Mana, Rio de Janeiro, v. 11, n. 2, Oct. 2005 . Disponível em: http://www.scielo.br/scielo.php?script=sci _arttext\&pid=S010493132005000200010\&lng=en\&nrm=iso. Acesso em 17 Julho 2014.

SOMEKH, N. A cidade vertical e o urbanismo modernizador. São Paulo: Studio Nobel, EDUSP, FAPESP 1997.

TEIXEIRA, M. C. S.; PORTO, M. do R. S. Violence, unsecurity and "imaginary of fear". Caderno CEDES, Campinas, v.19, n.47, p. 51-66, dezembro, 1998.

TULIK, O. O espaço rural aberto à segunda residência. In: LIMA, L. C. (Org.). Da cidade ao campo: a diversidade do saber-fazer turístico. Fortaleza: UECE, 1998. p. 201215.

VARELA, C. Que significa estar seguro? De delitos, miedos e inseguridades entre los adultos mayores. Cuadernos de Antropologia Social, Buenos Aires, n.22, jul./dez. 2005.

VELHO, G. A utopia urbana: um estudo de antropologia social. 6a. ed. Rio de Janeiro: Zahar, 2002. 